\title{
Biodegradable Chitosan Films with ZnO Nanoparticles Synthesized Using Food Industry By-Products-Production and Characterization
}

\author{
Victor Gomes Lauriano Souza ${ }^{1, *,+} \mathbb{D}^{\mathbb{D}}$, Marta M. Alves ${ }^{2} \mathbb{D}$, Catarina F. Santos ${ }^{2,3} \mathbb{D}$, Isabel A. C. Ribeiro ${ }^{4}$, \\ Carolina Rodrigues ${ }^{1}(\mathbb{D})$, Isabel Coelhoso ${ }^{5}$ (D) and Ana Luisa Fernando ${ }^{1}$ (D)
}

check for updates

Citation: Souza, V.G.L.; Alves, M.M.; Santos, C.F.; Ribeiro, I.A.C.;

Rodrigues, C.; Coelhoso, I.; Fernando,

A.L. Biodegradable Chitosan Films

with ZnO Nanoparticles Synthesized

Using Food Industry By-

Products-Production and

Characterization. Coatings 2021, 11,

646. https://doi.org/10.3390/

coatings 11060646

Academic Editor: Fengwei Xie

Received: 16 April 2021

Accepted: 24 May 2021

Published: 27 May 2021

Publisher's Note: MDPI stays neutral with regard to jurisdictional claims in published maps and institutional affiliations.

Copyright: (c) 2021 by the authors. Licensee MDPI, Basel, Switzerland. This article is an open access article distributed under the terms and conditions of the Creative Commons Attribution (CC BY) license (https:/ / creativecommons.org/licenses/by/ $4.0 /$ )
1 MEtRICs, Departamento de Ciências e Tecnologia da Biomassa, NOVA School of Science and Technology I FCT NOVA, Campus de Caparica, Universidade NOVA de Lisboa, 2829-516 Caparica, Portugal; cpe.rodrigues@campus.fct.unl.pt (C.R.); ala@fct.unl.pt (A.L.F.)

2 CQE Centro de Química Estrutural, Instituto Superior Técnico, Universidade de Lisboa, Av. Rovisco Pais, 1049-001 Lisboa, Portugal; martamalves@tecnico.ulisboa.pt (M.M.A.); catarina.santos@estsetubal.ips.pt (C.F.S.)

3 EST Setúbal, CDP2T, Instituto Politécnico de Setúbal, Campus IPS, 2910 Setúbal, Portugal

4 Research Institute for Medicines (iMed.ULisboa), Faculty of Pharmacy, Universidade de Lisboa, Avenida Prof. Gama Pinto, 1649-003 Lisboa, Portugal; ribeiroi@campus.ul.pt or iribeiro@ff.ulisboa.pt

5 LAQV-REQUIMTE, Departamento de Química, NOVA School of Science and Technology I FCT NOVA, Campus de Caparica, Universidade NOVA de Lisboa, 2829-516 Caparica, Portugal; imrc@fct.unl.pt

* Correspondence: victor.souza@inl.int

† Present address: INL, International Iberian Nanotechnology Laboratory, Av. Mestre José Veiga s/n, 4715-330 Braga, Portugal.

Abstract: This work aimed to produce bionanocomposites of chitosan incorporated with zinc oxide nanoparticles (ZnO NPs) synthesized using food industry by-products and to characterize them. Such nanoparticles are highlighted due to their low cost, antimicrobial activity, accessibility, and sustainability synthesis. Four different levels of ZnO NPs $(0,0.5,1.0$, and $2.0 \% w / w$ of chitosan) were tested, and the bionanocomposites were characterized in terms of their hydrophobicity, mechanical, optical, and barrier properties. Overall, the incorporation of ZnO NPs changed the composites from brittle to ductile, with enhanced elongation at break and reduced Young Modulus and tensile strength. Thus, ZnO NPs acted as plasticizer, turning the films more flexible, due to the presence of organic compounds on the NPs. This also favored permeability of oxygen and of water vapor, but the good barrier properties were maintained. Optical properties did not change statistically with the $\mathrm{ZnO}$ NPs incorporation. Thus, the characterization presented in this paper may contribute to support a decision on the choice of the material's final application.

Keywords: apple; zinc oxide; biopolymer; bionanocomposites; physical characterization

\section{Introduction}

Zinc oxide $(\mathrm{ZnO})$ has attracted intensive research efforts due to its unique properties that gives to $\mathrm{ZnO}$ a wide range of applicability, among which is being an antimicrobial agent [1]. Among the several methods used for $\mathrm{ZnO}$ synthesis, metallurgical or chemical methods, within the last ones, mechanochemical process, controlled precipitation, sol-gel method, solvothermal and hydrothermal method, method using emulsion and microemulsion environment, among others have been used to synthesize nanoparticles (NPs) [2]. Inside the chemical methods, green synthesis has been the preferred synthesis method as this is an environment-friendly, cost-effective, biocompatible, and safe approach, especially when aiming applications in the food industry [3]. The use of green synthesis supported by the use of plant extracts opens a wide range of possibilities for the synthesis of NPs with unique properties. This technique, when compared with other physicochemical methods [2], provides stable NPs with well-defined sizes and morphologies. Fruit 
extracts, well-known to reduce metal ions [4], depending on the source will confer unique characteristics to the NPs translating into a broad domain for novel nanomaterials [4]. This inexpensive and easily scaled-up method has a reduced environmental impact, that together with the use of food industry waste potentiate the entrance of ZnO NPs synthesis into the concept of circular economy, in particular when using apple (Malus domestica) peels, the fruit that is third place in world fruit production in 2017 , only after watermelon and banana [5].

An extensive piece of research on the green-synthesis of $\mathrm{ZnO}$ NPs using fruits extracts yielded the production of NPs with average sizes of 10 to $200 \mathrm{~nm}$, and the majority of NPs presenting a broad antimicrobial activity [6-10]. To the authors' best knowledge, from those studies, none report the synthesis with a common apple variety Golden Delicious. This is a commercial variety, thus, its peels are not limited as raw material, and its application on the NPs production will contribute to the circular economy and to reduce this food waste. Moreover, this variety is among the five top varieties produced in the European Union [11] and one of the varieties with higher polyphenol content in peels [12], to which an antibacterial activity has been associated [13].

Currently, the food industry has a great demand for new packaging materials, such as biopolymers as an alternative for the synthetic ones, which leads to a whole new field of research towards finding novel alternatives to fossil-based polymers [14-17].

Chitosan, a polysaccharide derived from the deacetylation of chitin, is the second most abundant biopolymer in nature and due to its properties can be used in food packaging as film or coating material [18-20]. Among these properties are included the biodegradability, non-toxicity, film-forming capacity, antimicrobial and antifungal efficacy, and the ability to act as a carrier for other substances [14,21]. Despite these excellent properties, chitosan has poor mechanical and barrier properties, which can limit its use, thus reinforcement materials, such as nanomaterials, are generally used to enhance these properties and overcome this drawback [22,23]. Chitosan pursues in its structure amine $\left(-\mathrm{NH}_{2}\right)$ and hydroxyl (-OH) groups, which are able to form complexes with multiple nanomaterials, such as metal nanoparticles and oxide agents, resulting in a reinforced material $[18,19,24]$. ZnO NPs are one of those nanomaterials that could be used to enhance not only mechanical but also chemical properties and enhance bioactivity [18,19]. ZnO NPs are also reported to increase antibacterial activity, mechanical strength, and barrier properties when added to food packaging materials [24,25]. The improvements on the barrier properties of chitosan films with the incorporation of ZnO NPs is related to the complex paths created, which make difficult the transport of the water or oxygen through the polymeric chain once the NPs fill the porous spaces within the macromolecule structure [23]. In the recent study of Yadav et al. [26], chitosan film was prepared with the incorporation of 1.5, 2.5, and $3.5 \mathrm{wt} \%$ of $\mathrm{ZnO}$ NPs loaded with gallic acid, and the bionanocomposites presented decreased water vapor permeability (WVP) and oxygen permeability (OP) proportionally to the amount of NPs added. The WVP reported was 66, 77, and $87 \%$ lower than the WVP of the pristine chitosan film for $1.5 \%, 2.5 \%$, and 3.5\% of ZnO NPs, respectively. The reduction in the OP was less effective, but still bionanocomposites presented a decrease from $7.5 \%$ to $41 \%$ in OP in comparison to neat chitosan film [26]. In terms of mechanical properties, this study obtained films with enhanced tensile strength and elongation at break when ZnO NPs incorporated concentration increased, which was attributed to the establishment of strong interfacial interactions with the chitosan matrix because of the NPs' large surface area that effectively filled the spaces in the polymer [26]. ZnO NPs are commonly incorporated in biodegradable bio-based polymers [25] to reinforce mechanical and barrier properties, but also to enhance/add antimicrobial activity, such as in carboxymethyl-chitosan [27], carboxymethyl cellulose (CMC) and chitosan [28], gelatin [29,30], PLA (poly-lactic acid) [31], CMC and okra mucilage [32], PLA-ZnO NPs nanocomposite coated paper [33], and chitosan [1,18,22,26,34-36]. Nevertheless, most of the papers use ZnO NPs synthesized using the traditional chemical methods. In our work, the ZnO NPs followed an eco-friendly production method that enriches the NPs 
also with active compounds (phenolic compounds), differentiating the type of ZnO NPs. In this eco-friendly process, the synthesis of ZnO NPs was done using peels of apples, thus, contributing to reduce food industry waste in a circular bio-economy concept. In our previous work [1], bionanocomposites based on chitosan incorporated with these ecofriendly $\mathrm{ZnO}$ NPs were produced and their bioactivity characterized by in vitro and in situ studies. Fresh poultry meat was used as the food matrix, once the thin films were produced as an alternative for food packaging material. The results obtained were promising, once the films were efficient in the extension of the shelf-life of the fresh poultry meat, and the incorporation of $\mathrm{ZnO}$ NPs enhanced the material's antimicrobial and antioxidant properties. Given the good results with these new bionanocomposites, the aim of this study was to evaluate the physical, morphological, and antibacterial properties of these chitosan films incorporated with these $\mathrm{ZnO}$ NPs to use them in food packaging, and therefore, to understand better how these ZnO NPs interact with the chitosan polymeric matrix, and its effect on the characteristics of the bionanocomposite.

\section{Materials and Methods}

\subsection{Chemicals}

$\mathrm{ZnO}$ nanoparticles were synthesized using zinc nitrate $\left(\mathrm{Zn}\left(\mathrm{NO}_{3}\right) 2.6 \mathrm{H}_{2} \mathrm{O}\right.$, SigmaAldrich, Steinheim, Germany) and potassium hydroxide ( $\mathrm{KOH}$, Sigma-Aldrich). Bionanocomposites were produced using chitosan (Poly(D-glucosamine), Sigma-Aldrich) with $75 \%$ of deacetylation and high molecular weight (31-37 kDa), glacial acetic acid (Alfa Aesar, Kandel, Germany) and glycerol (Alfa Aesar). Sodium bromide ( $\mathrm{NaBr}$ ), potassium acetate $\left(\mathrm{CH}_{3} \mathrm{COOK}-99 \%\right.$ purity) were purchased from Alfa Aesar, while sodium chloride $(\mathrm{NaCl})$, was obtained from PanReac (Barcelona, Spain). Pure oxygen (99.999\% purity) (Praxair, Madrid, Spain) was used in the oxygen permeability assay. All chemicals were of analytical reagent grade and the water purified using Milli-Q system (Millipore, Billerica, MA, USA).

\section{2. $\mathrm{ZnO}$ Nanoparticles (NPs) Synthesis}

Apple extract was prepared using commercial apples (Malus domestica) variety Golden Delicious. To ensure minimal variation from batch-to-batch extract production, only apples at commercial maturity were selected [37]. Once properly washed, fresh apples were peeled off and an extract of $0.2 \mathrm{~g}$ of fresh weight $(\mathrm{FW}) / \mathrm{mL}$ of peels was obtained after boiling in water for $20 \mathrm{~min}$. This extract was then filtered with gauze followed by a Whatmann (Maidstone, UK) No. 1 filter. For the synthesis of the NPs, zinc nitrate $2 \%(w / v)$ was added to the extract; upon its complete dissolution a $\mathrm{KOH} 1 \mathrm{M}$ solution was added (1:6 $(v / v))$ at room temperature. The synthesized NPS were filtered with a PM UC500 filter (Microdyn Nadir, Wiesbaden, Germany). The collected particles were dried overnight in a conventional oven (WTB binder, Munich, Germany) at $70{ }^{\circ} \mathrm{C}[1,38]$.

\section{3. $\mathrm{ZnO}$ NPs Characterization}

\subsubsection{Morphological and Chemical Studies}

The morphology and chemical composition of the NPs were characterized by scanning electron microscopy (SEM) using a JEOL-JSM7001F (Tokyo, Japan) apparatus corresponding X-ray energy dispersive spectrometer (EDS). The conductivity of the samples was improved with a thin coating of conductive gold/palladium (Polaron E-5100). For the transmission electron microscopy (TEM) studies, a Hitachi (Tokyo, Japan) H-9000-NA microscope operating at $200 \mathrm{kV}$ with supporting copper-carbon grids was used. The crystallinity was evaluated by X-ray diffraction (XRD) using a D8 Advance Bruker AXS $\theta-2 \theta$ diffractometer (Karlsruhe, Germany) with a copper radiation source $(\mathrm{Cu} \mathrm{K} \alpha, \lambda=1.5406 \AA)$ and a secondary monochromator operating at $40 \mathrm{kV}$ and $40 \mathrm{~mA}$. For the characterization of the organic groups present in the NPs, attenuated total reflectance (ATR) spectra were acquired with a Nicolet (Thermo Electron, Waltham, MA, USA) spectrometer. 


\subsubsection{Antibacterial Activity}

Antimicrobial activity of ZnO NPs was assessed towards Staphylococcus aureus (ATCC ${ }^{\circledR}$ $25923^{\mathrm{TM}}$ ) and Escherichia coli $\left(\mathrm{ATCC}^{\circledR} 25922^{\mathrm{TM}}\right.$ ). The Kirby-Bauer assay was performed and NPs disks with $18.6 \pm 0.8 \mathrm{mg}$ of $\mathrm{ZnO}$ NPs ( $\sim 6 \mathrm{~mm}$ diameter) were used. This assay was conducted according to the guidelines of the Clinical and Laboratory Standards Institute (CLSI) [39,40]. Briefly, aliquots from bacterial frozen stocks were used to culture microorganisms in Tryptic Soy Agar (Biokar Diagnostics, Allone, France) for $24 \mathrm{~h}$ at $37^{\circ} \mathrm{C}$. To prepare the inoculum, few colonies of each strain cultured in Tryptic Soy Agar were resuspended in Mueller Hinton Broth (Biokar Diagnostics) and further diluted in order to achieve $0.5 \mathrm{McF}$ arland units at a $600 \mathrm{~nm}$ wavelength, using a spectrophotometer (U2000, Hitachi). The inoculum was swabbed on Mueller Hinton Agar (Biokar Diagnostics) plates and the $\mathrm{ZnO}$ NPs disks were placed on the agar surface as well as $6 \mathrm{~mm}$ filter disks containing $5 \mu \mathrm{g}$ of levofloxacin (control). Petri dishes were further incubated (Ultima, Revco) at $37^{\circ} \mathrm{C}$ for $20 \mathrm{~h}$. After the incubation period, the inhibition zone diameters were measured using a vernier caliper. Assays were performed in three independent experiments [40].

\subsection{Bionanocomposites Film Preparation}

Films were produced by casting method with a film-forming dispersion (FFD) obtained by the dissolution of chitosan $(1.5 \%, w / v)$ in $1 \%(v / v)$ glacial acetic acid solution with constant stirring during $24 \mathrm{~h}$ at room temperature [1]. The plasticizer used was glycerol at the level of $30 \%$ ( $w / w$ of chitosan), and ZnO NPs were incorporated in three different proportions based on literature review and our previous work [1], namely $0.5,1$, and $2 \% w / w$ of chitosan. The amount of ZnO NPs generally incorporated in biopolymers is in the range between 0.1 [22] and 10\% [35]; however, concentrations higher than $2-3 \%$ tend to diminish the reinforcement capacity of the NPs due to agglomerations of the nanoparticles [35,36,41]. However, an extra bionanocomposite incorporated with more nanoparticles $(10 \% w / w$ of chitosan) was produced just to verify the chemical distribution on SEM. Films without NPs were used as control. The system was homogenized for $5 \mathrm{~min}$ with ultraturrax $(15,000 \mathrm{rpm})$ (IKA ${ }^{\circledR}$ T18, Staufen, Germany) and degassed in an ultrasound bath (Selecta, Barcelona, Spain) for $5 \mathrm{~min}(360 \mathrm{~W})$. Subsequently, the resulting dispersion was casted in glass molds $(18 \mathrm{~cm} \times 25 \mathrm{~cm})$ and naturally dried at room temperature for about $72 \mathrm{~h}$. Dried films were peeled and stored, protected from light at $25^{\circ} \mathrm{C}$ until evaluation.

\subsection{Film's Characterization}

\subsubsection{Morphological and Chemical Studies}

Surface and cross-section of the films were observed by SEM and EDS, as previously described. To improve the film conductivity, a thin coating of conductive gold/palladium was previously applied to the specimens (Polaron E-5100).

\subsubsection{Thickness and Mechanical Properties}

The thicknesses of the films were determined on ten random points of each sample using a digital micrometer $(0.001 \mathrm{~mm}$, Mitutoyo, Kawasaki, Japan). Mechanical properties were determined according to ASTM D882-12 [42], the parameters studied were elastic modulus (EM), tensile strength (TS), and percentage of elongation at break (EAB). Briefly, five strips of each film (150 mm wide and $25.4 \mathrm{~mm}$ long) were mounted in the tensile grips with a $0.5 \mathrm{kN}$ load cell (Autograph Shimadzu, Sydney, Australia), and an initial gauge length of $50 \mathrm{~mm}$. The system was then stretched at a cross-head speed of $50 \mathrm{~mm} / \mathrm{min}$ until breakage.

\subsubsection{Water Vapor Permeability (WVP)}

To calculate the WVP $\left(\mathrm{mol} \cdot \mathrm{m}^{-1} \cdot \mathrm{s}^{-1} \cdot \mathrm{Pa}^{-1}\right)$, disks with $45 \mathrm{~mm}$ diameter of each sample were cut and sealed on the top of glass cells containing $8 \mathrm{~mL}$ of saturated $\mathrm{NaCl}$ solution (Relative Humidity $(\mathrm{RH})=76.9 \%)$, subsequently the system was placed inside a desiccator 
containing saturated potassium acetate solution $(\mathrm{RH}=22.5 \%)$, periodically (regular time during approximately $24 \mathrm{~h}$ ) the cells were weighted (precision $0.0001 \mathrm{~g}$ ) to determine the water vapor flux. The assay was carried out at $30^{\circ} \mathrm{C}$, and to promote air circulation and maintain the driving force during the test, the desiccator was equipped with a fan. WVP was calculated by following Equation (1) [43]:

$$
\mathrm{WVP}=\frac{N_{W} \times \delta}{\Delta P_{\text {w.eff }}}
$$

where $N w\left(\mathrm{~mol} \cdot \mathrm{m}^{-2} \cdot \mathrm{s}^{-1}\right)$ is the water vapor flux, $\delta(\mathrm{m})$ is the film thickness, and $\Delta P_{\mathrm{w} . e f f}$ $(\mathrm{Pa})$ is the effective driving force. Results are the average \pm standard deviation of the three replicates analyzed.

\subsubsection{Oxygen Permeability (OP)}

Oxygen permeability was determined according to the methodology described by Ferreira et al. [43]. Previously to the test the specimens were equilibrated at $30{ }^{\circ} \mathrm{C}$ and relative humidity of $55 \% \pm 5 \%$ (desiccator containing saturated sodium bromide solution). The OP was assessed by the measurement of the pressure change in both chambers over time, using two pressure transducers (Jumo, Model 404327, Fulda, Germany). A thermostatic bath (Julabo, Model EH, Seelbach, Germany) was used to maintain the temperature at $30^{\circ} \mathrm{C}$. The $\mathrm{OP}$ was calculated using Equation (2):

$$
\frac{1}{\beta} \ln \left(\frac{\Delta p_{0}}{\Delta p}\right)=P \frac{t}{\delta}
$$

where $\Delta p$ (mbar) is the pressure difference between feed and permeate compartment, $P$ $\left(\mathrm{mol} \cdot \mathrm{m}^{-1} \cdot \mathrm{s}^{-1} \cdot \mathrm{Pa}^{-1}\right)$ is the gas permeability, $t(\mathrm{~s})$ is the time, $\delta(\mathrm{m})$ is the film thickness, and $\beta$ is the geometric parameter of cell [44].

\subsubsection{Optical Properties}

CIE- $L^{*} a^{*} b^{*}$ coordinates were measured from the film samples using a colorimeter CR 410 (Minolta Co., Tokyo, Japan) with a $10 \mathrm{~mm}$ diameter window, using D65 illuminant $/ 10^{\circ}$ observer. Chroma $\left(c^{*}\right)$ and hue angle (hue) were calculated according to Equations (3) and (4), respectively. Measurements were taken on standard white backgrounds [45].

$$
\begin{gathered}
c^{*}=\left(a^{* 2}+b^{* 2}\right)^{1 / 2} \\
\text { hue }=\arctan \left(\frac{b^{*}}{a^{*}}\right) \times \frac{180}{\pi} \text {, for } a^{*}>0 \text { and } b^{*}>0
\end{gathered}
$$

The opacity was calculated by direct reading of the absorbance of rectangular samples at $600 \mathrm{~nm}$ using UV/VIS spectrophotometer (Model Spekol 1500, Analytikjena, Jena, Germany) according to Equation (5) [46].

$$
\text { Opacity }\left(\mathrm{mm}^{-1}\right)=\frac{\text { absorbance } 600 \mathrm{~nm}}{\text { sample thickness }(\mathrm{mm})}
$$

Film transparency was evaluated through a spectrum scan (wavelengths between 190 and $900 \mathrm{~nm}$ ) of each film specimen using UV/VIS spectrophotometer. Results are expressed as percentage of transmittance, and air was used as reference [47].

\subsubsection{Solubility and Swelling Degree}

Solubility and swelling degree were calculated using Equations (6) and (7), respectively [48]. Briefly, film specimens were cut $(2 \mathrm{~cm} \times 2 \mathrm{~cm})$ and weighted (precision $0.0001 \mathrm{~g}$ ), obtaining the initial weight $\left(M_{1}\right)$; subsequently, the samples were dried in a conventional oven at $70{ }^{\circ} \mathrm{C}$ for $24 \mathrm{~h}$ to get the initial dry mass $\left(M_{2}\right)$. Then, samples were placed in 
a Petri dish containing $30 \mathrm{~mL}$ of water for $24 \mathrm{~h}$ at room temperature $\left(25^{\circ} \mathrm{C} \pm 2{ }^{\circ} \mathrm{C}\right)$, to allow the samples to swell the water. After this time, the water not absorbed by the film was discarded and the specimens were gently superficially dried with paper and weighted $\left(M_{3}\right)$. Finally, the residual film specimens were dried again in the oven at the same conditions used before to obtain the final dry mass $\left(M_{4}\right)$. For each film sample, two measurements were taken, and results were expressed in percentage of the average of the two determinations.

$$
\begin{gathered}
\% \text { Solubility }=\frac{\left(M_{2}-M_{4}\right)}{M_{2}} \times 100 \\
\% \text { Swelling degree }=\frac{\left(M_{3}-M_{2}\right)}{M_{2}} \times 100
\end{gathered}
$$

\subsubsection{Contact Angle (CA)}

Contact angle was determined at room temperature $\left(25^{\circ} \mathrm{C} \pm 2{ }^{\circ} \mathrm{C}\right)$ using a goniometer (KSV Instruments Ltd., CAM 100, Helsinki, Finland) with the software KSV CAM 100. The material's surface hydrophilicity was evaluated from water drops contact angles with their upper surface and expressed as the average on both sides of the drop [43].

\subsection{Statistical Analysis}

Film characterization was conducted using three replications. Statistical analysis of data was performed through a one-way analysis of variance (ANOVA) using the Software OriginLab, version 8.5 (OriginLab Corporation, Northampton, MA, USA). The differences among mean values were processed by the Tukey test. The significance was defined at $p<0.05$ and the results were expressed as the means of the replicates \pm standard deviation.

\section{Results}

\subsection{Characterization of the Green-Synthesized $\mathrm{ZnO}$ Nanoparticles}

Zinc oxide $(\mathrm{ZnO})$ crystals are typically formed by a top hexagonal polar zinc face, symmetric nonpolar planes directions, and a basal polar oxygen face $[49,50]$. Depending on the binding compounds present in the apple extract specific crystal faces growth can occur. As depicted in Figure 1a, the synthesized $\mathrm{ZnO}$ nanoparticles formed nanosphere-like agglomerates, which result from the agglomeration of lamina-like nanostructures with square and oval nano-morphologies (Figure 1b). To confirm the successful synthesis of $\mathrm{ZnO}$ crystals, the presence of $\mathrm{Zn}$ and of $\mathrm{O}$ was confirmed by EDS. Moreover, the metallic zinc ion was also measured by atomic absorption spectrometry (Zeenit 700, Analytikjena, Jena, Germany) after dissolving the ash residue of the mineralized ZnO NPs with nitric acid [51], and the concentration of this metal was around $41.3 \%$ ( $w / w$ of $\mathrm{ZnO}$ NPs). Furthermore, the $\mathrm{ZnO}$ NPs produced were rich in phenolic compounds from the apple peel used in the synthesis, a total phenolic content of $7.4 \mathrm{mg}$ Gallic acid equivalent/g of ZnO NPs [1] determined by the Folin-Ciocalteu method [52]. The typical crystalline structure of $\mathrm{ZnO}$ with the SAED pattern (Figure 1c) and XRD diffractogram (Figure 1d). In the SAED pattern (Figure 1c), the typical crystallographic planes assigned to $\mathrm{ZnO}$ were identified, namely (l $\left.\begin{array}{ll}1 & 0\end{array}\right),\left(\begin{array}{lll}0 & 0 & 2\end{array}\right),\left(\begin{array}{lll}1 & 0 & 1\end{array}\right),\left(\begin{array}{lll}1 & 0 & 2\end{array}\right),\left(\begin{array}{lll}1 & 1 & 0\end{array}\right),\left(\begin{array}{lll}1 & 0 & 3\end{array}\right)$, and $\left(\begin{array}{lll}1 & 1 & 2\end{array}\right)$. The XRD diffractograms besides confirming the presence of the peaks assigned to $\mathrm{ZnO}$, coincident with the JCPDS card 036-1451, gave information relating the average crystallite size of the NPs. By using the well-known Debye-Scherrer's equation, a crystallite size of $22.2 \mathrm{~nm}$ was estimated along $\left(\begin{array}{lll}0 & 0 & 2\end{array}\right)$ orientation (Figure 1d), confirming the nanoscale dimensions of the synthesized $\mathrm{ZnO}$ NPs. This result agrees with the average crystallite size of other ZnO NPs synthesized with fruit extracts of Citrus aurantifolia and Malus domestica with sizes ranging from 50 to $200 \mathrm{~nm}$ [5-10,38,53-60]. 


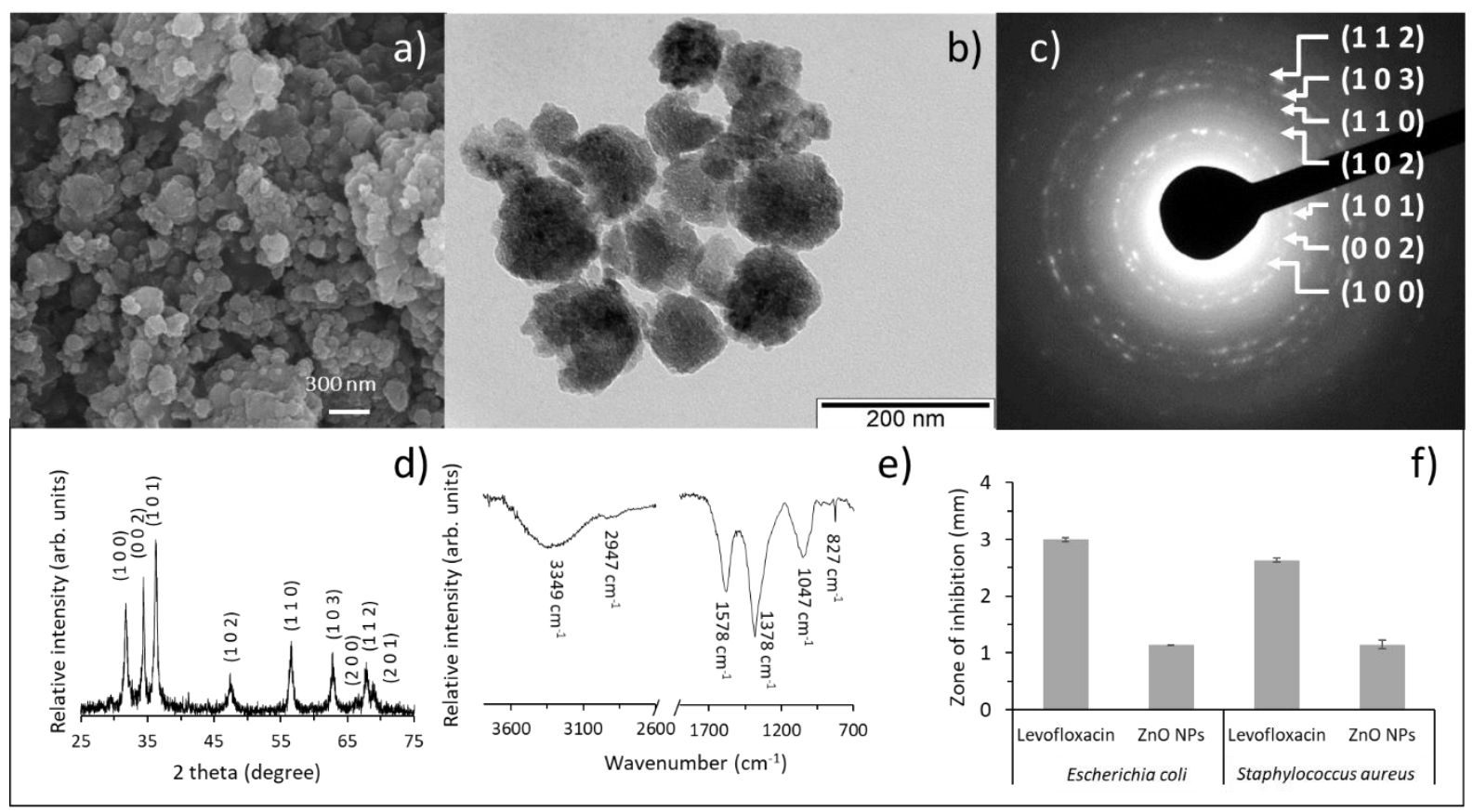

Figure 1. Green-synthesized $\mathrm{ZnO}$ nanoparticles using the peel extract of apple var. Golden, (a) scanning electron microscopy (SEM) and (b) transmission electron microscopy (TEM) images, with (c) the corresponding electron diffraction pattern (SAED), (d) X-ray diffraction (XRD) diffractogram with the crystallographic planes identified according with JCPDS data card 036-1451, (e) attenuated total reflection-Fourier transform infrared (ATR-FTIR) spectrum, and (f) antibacterial activity against Escherichia coli and Staphylococcus aureus.

To characterize the organic compounds bounded to the as-synthesized $\mathrm{ZnO}$ particles, attenuated total reflection-Fourier transform infrared (ATR-FTIR) analysis was performed. As observed in Figure 1e, a broad band at $3349 \mathrm{~cm}^{-1}$ can be assigned to O-H stretching, and that at $2947 \mathrm{~cm}^{-1}$ to the stretching of C-H bond. The peak at $1578 \mathrm{~cm}^{-1}$ can be related to the stretching vibration modes of $\mathrm{C}-\mathrm{C}$ and $\mathrm{C}=\mathrm{C}, \mathrm{C}-\mathrm{O}$ including those within aromatic rings. A peak at $1378 \mathrm{~cm}^{-1}$ relates with the stretching mode of $\mathrm{C}-\mathrm{H}$ bond. The bands in the region below $1300 \mathrm{~cm}^{-1}$ correspond to $\mathrm{C}-\mathrm{O}$ and $\mathrm{C}-\mathrm{C}$ stretching modes and/or to $\mathrm{C}-\mathrm{O}, \mathrm{O}-\mathrm{H}$ and $\mathrm{C}-\mathrm{H}$ bending modes. Finally, a sharp band at $827 \mathrm{~cm}^{-1}$ can be identified as the $\mathrm{Zn}-\mathrm{O}$ stretching mode [26]. Overall, the presence of chemically bonded organic molecules was confirmed for the as-synthesized particles [61]. Similarly, in ZnO NPs loaded with gallic acid [23], the formation of $\mathrm{ZnO}$ loaded with phenolic acids was inferred by the spectral band appearing at $736 \mathrm{~cm}^{-1}$ due to $\mathrm{Zn}-\mathrm{O}$ stretching vibration.

To assess the antibacterial potential of the synthesized NPs, relevant food pathogen species were tested (Figure 1f). Thus, ZnO NPs activity was evaluated against Gram negative and positive bacteria, E. coli and S. aureus, respectively. An inhibition zone was clearly visible for both stains (Figure 1f), although smaller than that of the antibiotic, these data indicate the antibacterial potential of the as-synthesized ZnO NPs against both bacterial strains. This behavior agrees with the antibacterial activity reported for other green-synthesized ZnO NPs [62].

Moreover, the inhibition zone observed for the antibiotic control ( $5 \mu \mathrm{g}$ of levofloxacin) was in accordance with the expected results for E. coli $(29-37 \mathrm{~mm})$ and S. aureus $(25-30 \mathrm{~mm})$ [63].

\subsection{Characterization of Chitosan Films Functionalized with the $\mathrm{ZnO}$ Nanoparticles}

To functionalize the film, the as-synthesized NPs were embedded in chitosan in different percentages. A pure chitosan film was morphologically compared with those having $0.5,1,2$, and $10 \%(w / w)$ of $\mathrm{ZnO} N P s$ (Figure 2). The top view (Figure 2a,e) and the cross-section (Figure 2f,j) images revealed that minor changes were depicted due to $\mathrm{ZnO}$ NPs addition. The top view images (Figure 2a-e) show that the percentages of ZnO NPs 
used in this study caused no morphological differences at the surfaces of the biocomposites. A deeper analysis of the cross-section images showed that the addition of ZnO NPs was not significantly changing the chitosan film thickness (Figure $2 \mathrm{f}-\mathrm{j}$ ). To assess the distribution of the NPs along the film, Zn content was analyzed by energy dispersive X-ray spectroscopy (EDS). The percentage of $\mathrm{Zn}$ in the film with $10 \%(w / w)$ of $\mathrm{ZnO}$ NPs has $6.7 \mathrm{At}$. \% of $\mathrm{Zn}$ and 40.2 At. \% of $C$, which came from the contribution of particles and chitosan, respectively. The presence of $\mathrm{O}$, both from ZnO NPs and chitosan is of 53.1 At. \%. The distribution of these elements, in the film with $10 \%(w / w)$ of ZnO NPs (Figure 2e,j), revealed that a homogeneous distribution of the NPs was attained within the polymeric matrix, with no detectable NPs agglomeration. This result clearly shows that the procedure used is adequate for the fabrication of this bionanocomposite.
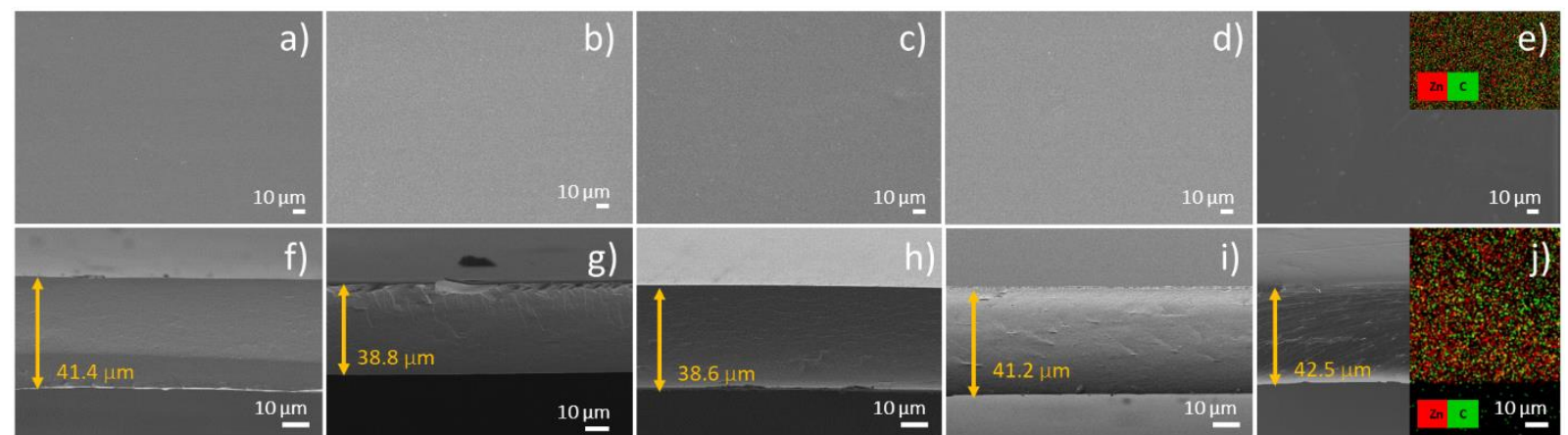

Figure 2. Scanning electron microscopy (SEM) images of the top (a-e) and cross-section view (f-j) of chitosan films functionalized with the green-synthesized ZnO NPs; film of $(\mathbf{a}, \mathbf{f})$ pure chitosan, films of chitosan with $(\mathbf{b}, \mathbf{g}) 0.5 \%(w / w)$, $(\mathbf{c}, \mathbf{h}) 1 \%(w / w),(\mathbf{d}, \mathbf{i}) 2 \%(w / w)$, and $(\mathbf{e}, \mathbf{j}) 10 \%(w / w)$ of $\mathrm{ZnO} N P s$; insets represent the elemental distribution of $\mathrm{Zn}$ and $\mathrm{C}$ in the film depicted by energy dispersive $\mathrm{X}$-ray spectroscopy (EDS).

Bionanocomposites incorporated with $10 \% \mathrm{ZnO}$ NPs were not fully characterized because in our previous study, where the films were tested in contact with fresh poultry meat [1], the amount of zinc that diffused toward the food packaged almost reached the maximum limit regulated by the European Food Safety Authority [64] for the films with $2 \% \mathrm{ZnO}$ NPs, i.e., superior percentages of nanoparticles would exceed the regulation, not fulfilling the requirements to be a food contact material, thus excluding the material final purpose.

\subsection{Thickness and Mechanical Properties}

Table 1 indicates the thickness and mechanical properties of the films. Pristine chitosan film exhibited $42 \mu \mathrm{m}$ thickness, whereas for the bionanocomposites it was 49.4, 49.6, and $59.3 \mu \mathrm{m}$ with $0.5,1$, and $2 \% \mathrm{ZnO}$ NPs incorporated, respectively. Despite the differences, the increment observed on the thickness with the incorporation of ZnO NPs was only statistically significant for the highest percentage tested $(p<0.05)$. Similar results were previously reported to soluble soybean polysaccharide films incorporated with ZnO NPs from 5-15\% [65], the authors attributed the changes to the increase in the roughness and the solid content of the nanocomposites. Other films based on polysaccharide and $\mathrm{ZnO}$ NPs also presented the same behavior of increase in the thickness with the incorporation of ZnO NPs [25], in this study, the polymeric matrices evaluated were agar, carrageenan, and carboxymethylcellulose (CMC), and the thickness of the nanocomposites were up to $81 \%$ higher than the control film. In comparison to our results, the maximum increment was only $42 \%$. Chitosan film incorporated with ZnO NPs loaded with gallic acid (ZnO@gal) at three levels $(1.5,2.5$, and $3.5 \mathrm{wt} \%)$ also presented increased thickness, except for the sample with 3.5 wt $\%$ ZnO@gal, which presented a 9\% reduction on this attribute in comparison to pristine chitosan film, contrary to what was observed in this work [26]. Moreover, in this study, the influence of $\mathrm{ZnO@gal} \mathrm{on} \mathrm{the} \mathrm{thickness} \mathrm{was} \mathrm{less} \mathrm{significant} \mathrm{than} \mathrm{in} \mathrm{our} \mathrm{results,}$ presenting a deviation on the thickness of $\pm 9 \%$ in comparison to the control. 
Table 1. Thickness and mechanical properties characterization.

\begin{tabular}{ccccc}
\hline Film & Thickness $(\mu \mathbf{m})$ & Tensile Strength (MPa) & EAB (\%) & Elastic Modulus (MPa) \\
\hline Control & $42.0 \pm 4^{\mathrm{B}} \mathrm{7}^{\mathrm{B}}$ & $46.7 \pm 2.1^{\mathrm{A}}$ & $17.9 \pm 1.5^{\mathrm{B}}$ & $2046 \pm 236^{\mathrm{A}}$ \\
$\mathrm{Ch}+0.5 \%$ ZnO NPs & $49.4 \pm 3.1^{\mathrm{AB}}$ & $32.3 \pm 1.7^{\mathrm{B}}$ & $45.9 \pm 5.9^{\mathrm{A}}$ & $254 \pm 121^{\mathrm{B}}$ \\
$\mathrm{Ch}+1.0 \%$ ZnO NPs & $49.6 \pm 5.3^{\mathrm{AB}}$ & $36.2 \pm 6.5^{\mathrm{B}}$ & $47.1 \pm 3.8^{\mathrm{A}}$ & $250 \pm 180^{\mathrm{B}}$ \\
$\mathrm{Ch}+2.0 \%$ ZnO NPs & $59.3 \pm 2.8^{\mathrm{A}}$ & $30.4 \pm 1.4^{\mathrm{B}}$ & $46.4 \pm 2.3^{\mathrm{A}}$ & $227^{\mathrm{B}} \pm 21^{\mathrm{B}}$ \\
\hline
\end{tabular}

${ }^{(A, B)}$ : Different superscripts within the same column indicate significant differences among samples $(p<0.05)$. Ch: chitosan; ZnO NPs: zinc oxide nanoparticles; EAB: Elongation at break.

The mechanical properties studied measure the stretch ability prior to break, film strength, and stiffness, which are important characteristics for food packaging materials [66]. Overall, the incorporation of ZnO NPs, regardless of the percentage incorporated, completely changed the mechanical properties of the films in comparison to control samples $(p<0.05)$. Films went from brittle to ductile; however, within the bionanocomposites, the differences were not statistically significant $(p>0.05)$ (Table 1). Pristine chitosan film presented a tensile strength of $46.7 \mathrm{MPa}$, the addition of NPs reduced this value in $30.8 \%$, $22.5 \%$, and $34.9 \%$ for $0.5 \%, 1 \%$, and $2 \% \mathrm{ZnO} \mathrm{NPs}$, respectively, but differences among biocomposites with $\mathrm{ZnO}$ NPs were not statistically significant. Elongation at break as expected presented a contrary behavior, once it is inversely related to tensile strength [66]. Finally, similarly to the tensile strength, elastic modulus also diminished with the incorporation of $\mathrm{ZnO}$ NPs, which means that a decrease in the material stiffness was observed. It is important to highlight that the synthesized NPs also have present phytochemicals (phenolic compounds) from the apple peels used in the synthesis, which chemically bond with the polymeric chain, changing the material's properties.

Our results are in good agreement with results previously reported for chitosan/methy lcellulose oleic acid and ZnO NPs [67], for agar, carrageenan, and CMC incorporated with ZnO NP [25], and for chitosan with ZnO NPs [41]. Noshirvani et al. [67] studied bionanocomposites incorporated with the same amount of ZnO NPs, and observed a reduction in tensile strength of $18 \%, 41 \%$, and $74 \%$ in comparison to control films when $0.5 \%, 1 \%$, and $2 \%$ of $\mathrm{ZnO}$ NPs were incorporated, respectively. This behavior is similar to what was verified in this work; however, in our study, the maximum difference was $35 \%$ for the highest amount of ZnO NPs incorporated. According to those authors, this phenomenon is probably due to the weak interfacial interaction between the polymer matrix and $\mathrm{ZnO}$ NPs $[25,67]$, but also the presence of $\mathrm{ZnO}$ NPs did not interrupt the movement of polymer chains [25], suggesting a plasticizing effect of ZnO NPs [67]. Indeed, the presence of phenolic compounds in the synthesized NPs could also have acted as plasticizers, and contributed to this change in the film's mechanical behavior, reflecting a similar trend that was also observed for bionanocomposites of chitosan/montmorillonite incorporated with rosemary essential oil $[68,69]$ and ginger essential oil [48]. The incorporation of phenolic compounds associated with the $\mathrm{ZnO}$ NPs into the polymeric matrix of films may have affected the mechanical resistance of the polymers by the partial replacement of the strong polar chemical bonds chitosan-chitosan (between the chitosan molecules) by weaker interactions between chitosan-phenolic compounds (active molecules present in the ZnO NPs). In addition, contrary to our results, the incorporation of other types of ZnO NPs increased TS and EM and reduced EAB, in studies with soluble soybean polysaccharide- [65] and chitosan-based [36] films. These different results show that mechanical properties depend on many factors such as the type of polymer, shape and concentration of NPs, distribution and the amount of inter and intermolecular interactions between chains of polymer and the organic compounds on the surface of the NPs, film forming conditions, and casting procedure, to mention a few $[66,67]$. 


\subsection{Gas Barrier Properties (WVP and OP), Contact Angle, Solubility in Water, and Swelling Degree}

Polysaccharides are characterized to have good barrier properties to oxygen and lower to water vapor [70]. Pristine chitosan film presented an OP of $0.18 \times 10^{-16} \mathrm{~mol} \mathrm{~m} / \mathrm{m}^{2} \cdot \mathrm{s} \cdot \mathrm{Pa}$ (Table 2), which is smaller than the permeability previously reported to $\mathrm{EVOH}\left(0.24 \times 10^{-16}\right.$ $\left.\mathrm{mol} \mathrm{m} / \mathrm{m}^{2} \cdot \mathrm{s} \cdot \mathrm{Pa}[71]\right)$, the packaging material considered as one of the best hydrophilic gas barriers used in the industry [72]. The incorporation of ZnO NPs, contrary to most of the results in literature, increased the oxygen barrier properties of the material $(p<0.05)$, except for $1 \% \mathrm{ZnO} N \mathrm{NS}$, where the OP was statistically the same as control films $(p>0.05)$. This result must be related to the presence of organic compounds bounded to the NPs (Figure 1e) which plasticized the materials, changing them to a more flexible/relaxed matrix, contributing to higher permeation of the gas, which corroborates the results of the mechanical properties. It is possible that the phenolic compounds in the ZnO NPs acted as a plasticizer of the chitosan films, as it increased the elongation capacity of the material (\%EAB, as previously discussed), thus increasing both the permeability to oxygen and also to water vapor. The plasticizers act as an internal lubricant, reducing the frictional forces between the polymer chains, and increasing the intermolecular space, thus allowing a greater mobility of the polymer chains and consequently facilitating the transport of gases [46-48]. At the lowest amount tested (0.5\%), the amount of ZnO NPs were probably not sufficient to enhance the barrier against oxygen, thus leading the phenolic compounds to play the plasticizer role, which increased the OP. When $1 \% \mathrm{ZnO}$ NPs were incorporated, more NPs were available to counterbalance the plasticizer effect of the phenolic compounds by reinforcing the barrier properties, which may explain the smaller OP within the bionanocomposites studied. Finally, with $2 \%$ of ZnO NPs, a slight increase in the OP can be explained by a possible agglomeration of the NPs within the chitosan chain, which resulted in a lower reinforcement, in comparison to the $1 \% \mathrm{ZnO}$ NPs films, although between the two bionanocomposites, the OP results did not differ significantly.

Table 2. Barrier and hydrophobicity properties.

\begin{tabular}{|c|c|c|c|c|c|}
\hline Film & $\begin{array}{c}\mathrm{OP}\left(10^{-16}\right. \\
\mathrm{mol} / \mathrm{m} \cdot \mathrm{s} \cdot \mathrm{Pa})\end{array}$ & $\begin{array}{l}\text { WVP }\left(10^{-11}\right. \\
\mathrm{mol} / \mathrm{m} \cdot \mathrm{s} \cdot \mathrm{Pa})\end{array}$ & Contact Angle $\left({ }^{\circ}\right)$ & $\begin{array}{c}\text { Solubility in } \\
\text { Water (\%) }\end{array}$ & Swelling (\%) \\
\hline Control & $0.18 \pm 0.05^{C}$ & $1.54 \pm 0.18^{\mathrm{B}}$ & $71 \pm 5^{\mathrm{A}}$ & $25 \pm 0 \mathrm{AB}$ & $110 \pm 2^{A}$ \\
\hline $\mathrm{Ch}+0.5 \% \mathrm{ZnO}$ NPs & $0.98 \pm 0.13^{\mathrm{A}}$ & $2.21 \pm 0.03^{\mathrm{A}}$ & $82 \pm 5^{\mathrm{A}}$ & $22 \pm 2^{B}$ & $140 \pm 30^{\mathrm{A}}$ \\
\hline $\mathrm{Ch}+1.0 \% \mathrm{ZnO}$ NPs & $0.42 \pm 0.12^{\mathrm{BC}}$ & $2.40 \pm 0.24 \mathrm{~A}$ & $82 \pm 2^{A}$ & $22 \pm 1^{B}$ & $162 \pm 31^{\mathrm{A}}$ \\
\hline $\mathrm{Ch}+2.0 \% \mathrm{ZnO}$ NPs & $0.61 \pm 0.13^{\mathrm{B}}$ & $1.64 \pm 0.02^{\mathrm{B}}$ & $80 \pm 8^{\mathrm{A}}$ & $26 \pm 1^{A}$ & $171 \pm 35^{\mathrm{A}}$ \\
\hline
\end{tabular}

${ }^{(A-C)}$ : Different superscripts within the same column indicate significant differences among samples $(p<0.05)$. Ch: chitosan; ZnO NPs: zinc oxide nanoparticles. OP-Oxygen permeability; WVP-Water vapor permeability.

In the literature, studies addressing the determination of OP were not as abundant as those with WVP [23], probably due to the more complex methods or the demand for equipment to determine OP. However, in comparison to the data reported by Yadav et al. [26], our results presented the opposite pattern, once bionanocomposites slightly increased OP with the incorporation of ZnO NPs, while reductions of 7.5 and $10.9 \%$ in the OP of chitosan incorporated with 1.5 and 2.5\% of ZnO@gal [26], respectively, were observed. Despite this behavior, overall, the material maintained the good barrier properties of the original chitosan film, and the nanoparticles did not drastically change this positive characteristic. Furthermore, the OP results also corroborate with our previous work, where these bionanocomposites were used to preserve fresh poultry meat [1], and the samples protected with the $\mathrm{Ch}+1 \% \mathrm{ZnO}$ NPs showed the smallest oxidation over the refrigerated storage, which might have been associated to this superior oxygen barrier of the films that helped to prevent the oxidation to occur.

Water vapor permeability measures the rate of moisture that crosses the film, being an important property to be accounted for in packaging applications [36]. In general, WVP of chitosan film tends to diminish with the incorporation of ZnO NPs, as previously 
reported in Rahman et al. [36], Yadav et al. [26], which is generally explained by the physical crosslinking of the nanocomposite, which will diminish the diffusion of water vapor [26]. As aforementioned, in our work the increased WVP with the incorporation of ZnO NPS was unexpected, and it is probably related to the presence of the phenolic compounds, which reduced the amount of nanoparticles to crosslink within the chitosan chain and act as a reinforce material. As already stated, it is possible that the phenolic compounds in the $\mathrm{ZnO}$ NPs acted as a plasticizer of the chitosan films, as it increased the elongation capacity of the material, thus increasing both the permeability to gases and water vapor. Yet, the highest level tested $2 \%$ and presented a WPV statistically equal to pristine chitosan film $(p>0.05)$ (Table 2). At $2 \%$, the films were more capable to bind with the water, once they presented the highest swelling index, which can explain this diminishing on the WVP due to the decrease in the water vapor diffusion through the films. However, it should be stressed that overall, the incorporation of ZnO NPs did not drastically change the material's barrier properties, suggesting that well organized bonding between the polymer and the organic groups on the NPs surface was achieved. Results obtained are also in agreement with another study [36], where chitosan films were also reinforced with $\mathrm{ZnO}$ NPs at 4 different levels, $0.5,1,1.5$, and $2 \%$. In this study, it was observed that films incorporated with $1 \%$ also presented the highest water vapor transmission rate, which corroborates to what was observed in our study. The authors attributed this result to the unique feature of the films with $1 \% \mathrm{ZnO}$ NPs as revealed by mechanical property analysis.

Contact angle and swelling index did not statistically change $(p>0.05)$ with the incorporation of ZnO NPs, a result that agrees with the minor morphological changes previously described on these bionanocomposite surfaces (Figure 2), while the solubility in water decreased around $10 \%$ for 0.5 or $1 \%$ of $\mathrm{ZnO}(p<0.05)$, and did not statistically change when $2 \%$ was incorporated $(p>0.05)$ (Table 2$)$. The contact angle of the films depends on surface hydrophobicity and roughness, high CA is characteristic of hydrophobic surfaces [67]. Once hydrophobic surfaces are suitable for food packaging, the results presented are favorable for the purpose this material was produced for. Similar results were presented for agar $\mathrm{ZnO}$ bionanocomposites, whereas the NPs slightly increased the water contact angle, but with no statistical significance [73].

The stability of food packaging material in the presence of solvent molecules present on the surface of the foodstuff packaged is measured by water solubility index [18]. Overall, the percentage of solubility in water decreased with the incorporation of ZnO NPs up to $1 \%$, and with $2 \%$ of $\mathrm{ZnO}$ NP the difference was not significant in comparison to the control film. In the polymer chain, NPs have probably decreased the availability of hydrophilic groups for interaction with water, once cross link bonds between the NPs and chitosan chains are made through the polymer hydrophilic functional groups [18].

The water adsorption capacity of the films was studied by measuring their swelling index. Chitosan ability to swell water is related to the presence of a large number of hydrophilic groups in the polymer chain [74,75]. The incorporation of ZnO NPs, despite the differences not being statistically significant, increase the adsorption capacity of the bionanocomposites proportionally to the amount of ZnO NPs incorporated. Our findings are in good agreement with the results presented in the study of Rahman et al. (2017) [18]. According to these authors, this increment on the swelling index is due to the increase on the heterogeneity of the composite films created by the incorporation of ZnO NPs onto the chitosan matrix together with the formation of cavities in the films which pave the way for more adsorption of water molecules. Moreover, as this material was already used as primary packaging for fresh poultry meat [1], the water molecules in the surface of meat pose a risk to the product as they are highly vulnerable to microbial contamination, thus, this ability of the packaging to quickly adsorb water molecules has an important role in extending the shelf life of fresh meat [18]. 


\subsection{Optical Properties}

Optical property characterization is depicted in Table 3. Food packaging material must keep their transparency once it is a desirable characteristic to assure the good appearance of the food packaged, which may interfere on the product's acceptance by the consumers $[76,77]$. Overall, the transparency was not interfered by the incorporation of ZnO NPs (Figure 3), in fact the opacity was slightly enhanced (Table 3); however, with no statistical significance $(p<0.05)$. A similar trend was also reported in the recent study of Yadav et al. [26] that developed chitosan films incorporated with ZnO NP loaded with gallic acid. The material became more opaque with the nanoparticles incorporation. From the UV-Vis absorption spectra (Figure 3), it is also possible to point out a peak at $322 \mathrm{~nm}$ for all films incorporated with ZnO NPs. According to Dananjaya et al. [34], ZnO NPs present an absorption maxima around $365 \mathrm{~nm}$, which is assigned to the intrinsic band-gap absorption of $\mathrm{ZnO} N P s$ due to the electron transitions from the valence band to the conduction band $\left(\mathrm{O}_{2 p} \rightarrow \mathrm{Zn}_{3 \mathrm{~d}}\right)$. However, this absorption maximum underwent a blue-shift to around $322 \mathrm{~nm}$ in the bionanocomposites due to the interaction with the chitosan [34]. The material showed yellowish color, hue around $110^{\circ}$, characteristic of chitosan films, and the incorporation of $\mathrm{ZnO} N P s$ slightly increased this value, but only with statistical significance for $0.5 \% \mathrm{ZnO}$ NPs $(p<0.05)$ (Table 3$)$. The increase on Hue means that the composite showed a tendency to a greener color. The nanoparticles also influenced the Chroma by reducing the color saturation of the composites $(p<0.05)$, the coordinates $L^{*}, a^{*}$, and $b^{*}$ reduced with the incorporation of the nanoparticles (data not shown), resulting in this decrease on Chroma parameter. Contrary to what was observed in this work, in general the incorporation of $\mathrm{ZnO}$ NPs reduces the transparency of the composite, especially at UV wavelength, due to the light scattering through the film with a heterogeneous network of undissolved inorganic material within the polymer [28,30]. However, the composites maintained the good UV light barrier properties characteristic of neat chitosan film without sacrificing its transparency, which enables these composite films to be used as an active food packaging material to prevent UV light-induced oxidation of foods [30].

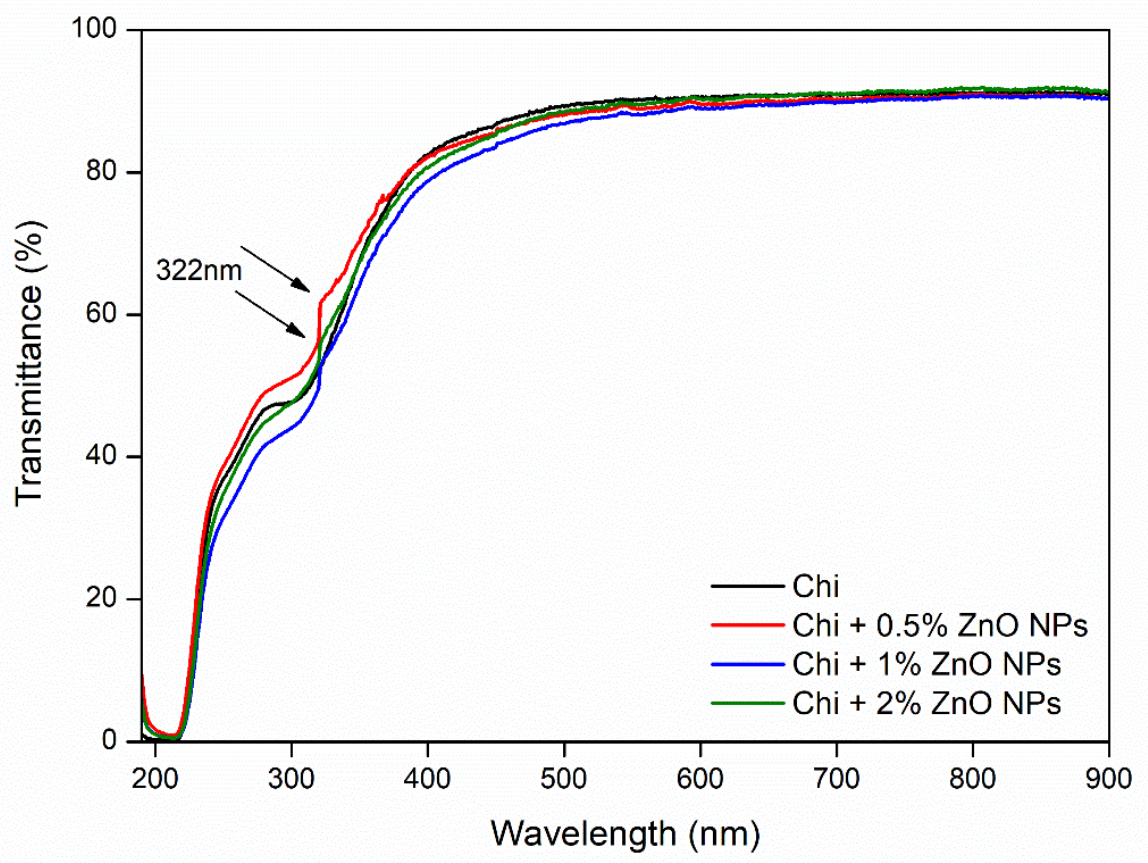

Figure 3. Bionanocomposites transparency. Chi: chitosan; ZnO NPs: zinc oxide nanoparticles. 
Table 3. Optical properties characterization.

\begin{tabular}{cccc}
\hline Film & Opacity $\left(\mathbf{m m}^{-\mathbf{1}}\right)$ & Chroma & Hue $\left.\mathbf{(}^{\circ}\right)$ \\
\hline Control & $0.96 \pm 0.11^{\mathrm{A}}$ & $6.22 \pm 0.42^{\mathrm{A}}$ & $111 \pm 2^{\mathrm{B}}$ \\
$\mathrm{Ch}+0.5 \%$ ZnO NPs & $1.03 \pm 0.09^{\mathrm{A}}$ & $4.31 \pm 0.59^{\mathrm{C}}$ & $117 \pm 3^{\mathrm{A}}$ \\
$\mathrm{Ch}+1.0 \%$ ZnO NPs & $1.00 \pm 0.19^{\mathrm{A}}$ & $4.49 \pm 0.42^{\mathrm{BC}}$ & $114 \pm 1^{\mathrm{AB}}$ \\
$\mathrm{Ch}+2.0 \%$ ZnO NPs & $1.01 \pm 0.19^{\mathrm{A}}$ & $5.47 \pm 0.19^{\mathrm{AB}}$ & $112 \pm 1^{\mathrm{B}}$ \\
\hline
\end{tabular}

$(\mathrm{A-C})$ : Different superscripts within the same column indicate significant differences among samples $(p<0.05)$ Ch: chitosan; ZnO NPs: zinc oxide nanoparticles.

\section{Conclusions}

Functionalized bio-based films with ZnO NPs were successfully casted and the nanoparticles' synthesis using a by-product from the food industry demonstrated to produce particles in a nanometer scale, with antimicrobial properties. The incorporation of ZnO NPs into chitosan films did not drastically change the material's properties, except for the mechanical behavior, that switched from brittle to ductile, with reductions between $22-35 \%$, and $88-89 \%$ on tensile strength and elastic modulus, respectively. The presence of phenolic compounds residues in the $\mathrm{ZnO}$ NPs produced may also have contributed to the results, once those compounds can also interact with chitosan chain. The nanoparticles produced did not present a reinforcement characteristic. Thus, if the incorporation of $\mathrm{ZnO}$ NPs aims to reinforce the polymer material, the nanoparticles produced with this method did not satisfactory accomplish this task. However they can enhance the material's bioactivity by adding their antimicrobial property and a further antioxidant capacity due to the phenolic compounds present, as reported in our previous work [1]. Moreover, the good barrier properties are maintained, and the nanoparticles do not drastically change this positive characteristic, allowing these films to be used in food packaging.

Author Contributions: Conceptualization, V.G.L.S., M.M.A., C.F.S., I.C. and A.L.F.; methodology, V.G.L.S., M.M.A., C.F.S. and I.A.C.R.; formal analysis, V.G.L.S., M.M.A., C.F.S., I.A.C.R. and C.R.; investigation, V.G.L.S., M.M.A., C.F.S., I.A.C.R. and C.R.; resources, M.M.A., C.F.S., I.A.C.R., I.C. and A.L.F.; writing-original draft preparation, V.G.L.S., M.M.A., C.F.S. and I.A.C.R.; writing-review and editing, M.M.A., C.F.S., I.A.C.R., I.C. and A.L.F.; supervision, I.C. and A.L.F.; funding acquisition, M.M.A., C.F.S., I.A.C.R., I.C. and A.L.F. All authors have read and agreed to the published version of the manuscript.

Funding: This research was funded by Foundation for Science and Technology-FCT (grant numbers UIDB/00100/2020 (CQE affiliated); UIDB/04077/2020 and UIDP/04077/2020 (MEtRICs); UIDB/50006/2020 and UIDP/50006/2020 (LAQV); Project PTDC/BTM-SAL/29335/2017 and UIDB/ $04138 / 2020$ and UIDP/04138/2020 (iMed)). This research was also funded by national funding by Foundation for Science and Technology—FCT, through the individual research grant (2020.04441.BD) of C.R.

Institutional Review Board Statement: Not applicable.

Informed Consent Statement: Not applicable.

Data Availability Statement: Data is contained within the article.

Conflicts of Interest: The authors declare no conflict of interest.

\section{References}

1. Souza, V.G.L.; Rodrigues, C.; Valente, S.; Pimenta, C.; Pires, J.R.A.; Alves, M.M.; Santos, C.F.; Coelhoso, I.M.; Fernando, A.L. Eco-Friendly ZnO/Chitosan Bionanocomposites Films for Packaging of Fresh Poultry Meat. Coatings 2020, 10, 110. [CrossRef]

2. Kołodziejczak-Radzimska, A.; Jesionowski, T. Zinc Oxide-From Synthesis to Application: A Review. Materials 2014, 7, $2833-2881$. [CrossRef] [PubMed]

3. Bandeira, M.; Giovanela, M.; Roesch-Ely, M.; Devine, D.M.; Crespo, J.D.S. Green synthesis of zinc oxide nanoparticles: A review of the synthesis methodology and mechanism of formation. Sustain. Chem. Pharm. 2020, 15, 100223. [CrossRef]

4. Schröfel, A.; Kratošová, G.; Šafařík, I.; Šafař́ková, M.; Raška, I.; Shor, L.M. Applications of biosynthesized metallic nanoparticlesA review. Acta Biomater. 2014, 10, 4023-4042. [CrossRef] [PubMed] 
5. Food and Agricultural Organization. FAOSTAT. Available online: http://www.fao.org/faostat/en/ (accessed on 29 July 2018 ).

6. Samat, N.A.; Nor, R.M. Sol-gel synthesis of zinc oxide nanoparticles using Citrus aurantifolia extracts. Ceram. Int. 2013, 39, S545-S548. [CrossRef]

7. Vimala, K.; Sundarraj, S.; Paulpandi, M.; Vengatesan, S.; Kannan, S. Green synthesized doxorubicin loaded zinc oxide nanoparticles regulates the Bax and Bcl-2 expression in breast and colon carcinoma. Process Biochem. 2014, 49, 160-172. [CrossRef]

8. Nagajyothi, P.; An, T.N.M.; Sreekanth, T.; Lee, J.-I.; Lee, D.J.; Lee, K. Green route biosynthesis: Characterization and catalytic activity of $\mathrm{ZnO}$ nanoparticles. Mater. Lett. 2013, 108, 160-163. [CrossRef]

9. Suresh, D.; Shobharani, R.; Nethravathi, P.; Kumar, M.P.; Bhushana, N.; Sharma, S. Artocarpus gomezianus aided green synthesis of $\mathrm{ZnO}$ nanoparticles: Luminescence, photocatalytic and antioxidant properties. Spectrochim. Acta Part A Mol. Biomol. Spectrosc. 2015, 141, 128-134. [CrossRef] [PubMed]

10. Yuvakkumar, R.; Suresh, J.; Nathanael, A.J.; Sundrarajan, M.; Hong, S. Novel green synthetic strategy to prepare ZnO nanocrystals using rambutan (Nephelium lappaceum L.) peel extract and its antibacterial applications. Mater. Sci. Eng. C 2014, 41, 17-27. [CrossRef] [PubMed]

11. European Union (EU) Apple Market in European Union. Available online: https://ec.europa.eu/info/sites/default/files/foodfarming-fisheries/farming/documents/apple-dashboard_en.pdf (accessed on 14 May 2021).

12. Kalinowska, M.; Bielawska, A.; Lewandowska, H.; Priebe, W.; Lewandowski, W. Apples: Content of phenolic compounds vs. variety, part of apple and cultivation model, extraction of phenolic compounds, biological properties. Plant Physiol. Biochem. 2014, 84, 169-188. [CrossRef]

13. Patocka, J.; Bhardwaj, K.; Klimova, B.; Nepovimova, E.; Wu, Q.; Landi, M.; Kuca, K.; Valis, M.; Wu, W. Malus domestica: A Review on Nutritional Features, Chemical Composition, Traditional and Medicinal Value. Plants 2020, 9, 1408. [CrossRef]

14. Divsalar, E.; Tajik, H.; Moradi, M.; Forough, M.; Lotfi, M.; Kuswandi, B. Characterization of cellulosic paper coated with chitosan-zinc oxide nanocomposite containing nisin and its application in packaging of UF cheese. Int. J. Biol. Macromol. 2018, 109, 1311-1318. [CrossRef]

15. Severo, C.; Anjos, I.; Souza, V.G.; Canejo, J.P.; Bronze, M.; Fernando, A.L.; Coelhoso, I.; Bettencourt, A.F.; Ribeiro, I.A. Development of cranberry extract films for the enhancement of food packaging antimicrobial properties. Food Packag. Shelf Life 2021, $28,100646$. [CrossRef]

16. Andrade, M.; Barbosa, C.; Souza, V.; Coelhoso, I.; Reboleira, J.; Bernardino, S.; Ganhão, R.; Mendes, S.; Fernando, A.; Vilarinho, F.; et al. Novel Active Food Packaging Films Based on Whey Protein Incorporated with Seaweed Extract: Development, Characterization, and Application in Fresh Poultry Meat. Coatings 2021, 11, 229. [CrossRef]

17. Rodrigues, C.; Souza, V.; Coelhoso, I.; Fernando, A. Bio-Based Sensors for Smart Food Packaging-Current Applications and Future Trends. Sensors 2021, 21, 2148. [CrossRef] [PubMed]

18. Rahman, P.M.; Mujeeb, V.A.; Muraleedharan, K. Flexible chitosan-nano ZnO antimicrobial pouches as a new material for extending the shelf life of raw meat. Int. J. Biol. Macromol. 2017, 97, 382-391. [CrossRef] [PubMed]

19. Çınar, S.; Kaynar, Ü.H.; Aydemir, T.; Kaynar, S.Ç.; Ayvacıklı, M. An efficient removal of RB5 from aqueous solution by adsorption onto nano-ZnO/Chitosan composite beads. Int. J. Biol. Macromol. 2017, 96, 459-465. [CrossRef]

20. Souza, V.G.L.; Pires, J.R.A.; Rodrigues, C.; Coelhoso, I.M.; Fernando, A.L. Chitosan Composites in Packaging Industry-Current Trends and Future Challenges. Polymers 2020, 12, 417. [CrossRef]

21. Souza, V.G.L.; Rodrigues, C.; Ferreira, L.; Pires, J.R.A.; Duarte, M.P.; Coelhoso, I.; Fernando, A.L. In vitro bioactivity of novel chitosan bionanocomposites incorporated with different essential oils. Ind. Crop. Prod. 2019, 140, 111563. [CrossRef]

22. Sanuja, S.; Agalya, A.; Umapathy, M. Synthesis and characterization of zinc oxide-neem oil-chitosan bionanocomposite for food packaging application. Int. J. Biol. Macromol. 2015, 74, 76-84. [CrossRef] [PubMed]

23. Pires, J.; de Paula, C.D.; Souza, V.G.L.; Fernando, A.L.; Coelhoso, I. Understanding the Barrier and Mechanical Behavior of Different Nanofillers in Chitosan Films for Food Packaging. Polymers 2021, 13, 721. [CrossRef]

24. Al-Naamani, L.; Dobretsov, S.; Dutta, J. Chitosan-zinc oxide nanoparticle composite coating for active food packaging applications. Innov. Food Sci. Emerg. Technol. 2016, 38, 231-237. [CrossRef]

25. Kanmani, P.; Rhim, J.-W. Properties and characterization of bionanocomposite films prepared with various biopolymers and $\mathrm{ZnO}$ nanoparticles. Carbohydr. Polym. 2014, 106, 190-199. [CrossRef]

26. Yadav, S.; Mehrotra, G.; Dutta, P. Chitosan based ZnO nanoparticles loaded gallic-acid films for active food packaging. Food Chem. 2021, 334, 127605. [CrossRef] [PubMed]

27. Zhong, Q.; Tian, J.; Liu, T.; Guo, Z.; Ding, S.; Li, H. Preparation and antibacterial properties of carboxymethyl chitosan/ZnO nanocomposite microspheres with enhanced biocompatibility. Mater. Lett. 2018, 212, 58-61. [CrossRef]

28. Noshirvani, N.; Ghanbarzadeh, B.; Mokarram, R.R.; Hashemi, M. Novel active packaging based on carboxymethyl cellulosechitosan-ZnO NPs nanocomposite for increasing the shelf life of bread. Food Packag. Shelf Life 2017, 11, 106-114. [CrossRef]

29. Shankar, S.; Teng, X.; Li, G.; Rhim, J.-W. Preparation, characterization, and antimicrobial activity of gelatin/ZnO nanocomposite films. Food Hydrocoll. 2015, 45, 264-271. [CrossRef]

30. Ejaz, M.; Arfat, Y.A.; Mulla, M.; Ahmed, J. Zinc oxide nanorods/clove essential oil incorporated Type B gelatin composite films and its applicability for shrimp packaging. Food Packag. Shelf Life 2018, 15, 113-121. [CrossRef]

31. Shankar, S.; Wang, L.-F.; Rhim, J.-W. Incorporation of zinc oxide nanoparticles improved the mechanical, water vapor barrier, UV-light barrier, and antibacterial properties of PLA-based nanocomposite films. Mater. Sci. Eng. C 2018, 93, 289-298. [CrossRef] 
32. Mohammadi, H.; Kamkar, A.; Misaghi, A.; Zunabovic-Pichler, M.; Fatehi, S. Nanocomposite films with CMC, okra mucilage, and ZnO nanoparticles: Extending the shelf-life of chicken breast meat. Food Packag. Shelf Life 2019, 21, 100330. [CrossRef]

33. Zhang, H.; Hortal, M.; Jordá-Beneyto, M.; Rosa, E.; Lara-Lledo, M.; Lorente, I. ZnO-PLA nanocomposite coated paper for antimicrobial packaging application. LWT 2017, 78, 250-257. [CrossRef]

34. Dananjaya, S.; Kumar, R.S.; Yang, M.; Nikapitiya, C.; Lee, J.; De Zoysa, M. Synthesis, characterization of ZnO-chitosan nanocomposites and evaluation of its antifungal activity against pathogenic Candida albicans. Int. J. Biol. Macromol. 2018, 108, 1281-1288. [CrossRef]

35. Li, L.-H.; Deng, J.-C.; Deng, H.-R.; Liu, Z.-L.; Xin, L. Synthesis and characterization of chitosan/ZnO nanoparticle composite membranes. Carbohydr. Res. 2010, 345, 994-998. [CrossRef] [PubMed]

36. Rahman, P.M.; Mujeeb, V.A.; Muraleedharan, K.; Thomas, S.K. Chitosan/nano ZnO composite films: Enhanced mechanical, antimicrobial and dielectric properties. Arab. J. Chem. 2018, 11, 120-127. [CrossRef]

37. Vrhovsek, U.; Rigo, A.; Tonon, D.; Mattivi, F. Quantitation of Polyphenols in Different Apple Varieties. J. Agric. Food Chem. 2004, 52, 6532-6538. [CrossRef]

38. Alves, M.M.; Andrade, S.M.; Grenho, L.; Fernandes, M.H.; Santos, C.; Montemor, M.F. Influence of apple phytochemicals in ZnO nanoparticles formation, photoluminescence and biocompatibility for biomedical applications. Mater. Sci. Eng. C 2019, $101,76-87$. [CrossRef] [PubMed]

39. CLSI M02-A12 Performance Standards for Antimicrobial Disk, 12th ed.; Clinical and Laboratory Standards Institute: Wayne, PA, USA, 2015; Volume 32, ISBN 1562389858.

40. Martin, V.; Ribeiro, I.A.; Alves, M.M.; Gonçalves, L.; Claudio, R.A.; Grenho, L.; Fernandes, M.H.; Gomes, P.; Santos, C.F.; Bettencourt, A.F. Engineering a multifunctional 3D-printed PLA-collagen-minocycline-nanoHydroxyapatite scaffold with combined antimicrobial and osteogenic effects for bone regeneration. Mater. Sci. Eng. C 2019, 101, 15-26. [CrossRef] [PubMed]

41. Boura-Theodoridou, O.; Giannakas, A.; Katapodis, P.; Stamatis, H.; Ladavos, A.; Barkoula, N.-M. Performance of ZnO/chitosan nanocomposite films for antimicrobial packaging applications as a function of $\mathrm{NaOH}$ treatment and glycerol/PVOH blending. Food Packag. Shelf Life 2020, 23, 100456. [CrossRef]

42. ASTM Standard Test Method for Tensile Properties of Thin Plastic Sheeting-D882-12; ASTM: West Conshohocken, PA, USA, 2012; Volume D882-12.

43. Ferreira, A.R.V.; Torres, C.A.V.; Freitas, F.; Sevrin, C.; Grandfils, C.; Reis, M.A.M.; Alves, V.D.; Coelhoso, I.M. Development and characterization of bilayer films of FucoPol and chitosan. Carbohydr. Polym. 2016, 147, 8-15. [CrossRef]

44. Alves, V.D.; Costa, N.; Coelhoso, I.M. Barrier properties of biodegradable composite films based on kappa-carrageenan/pectin blends and mica flakes. Carbohydr. Polym. 2010, 79, 269-276. [CrossRef]

45. Pastor, C.; Sánchez-González, L.; Chiralt, A.; Cháfer, M.; González-Martínez, C. Physical and antioxidant properties of chitosan and methylcellulose based films containing resveratrol. Food Hydrocoll. 2013, 30, 272-280. [CrossRef]

46. Park, S.-I.; Zhao, Y. Incorporation of a High Concentration of Mineral or Vitamin into Chitosan-Based Films. J. Agric. Food Chem. 2004, 52, 1933-1939. [CrossRef]

47. Kanatt, S.R.; Rao, M.; Chawla, S.; Sharma, A. Active chitosan-polyvinyl alcohol films with natural extracts. Food Hydrocoll. 2012, 29, 290-297. [CrossRef]

48. Souza, V.G.L.; Pires, J.R.A.; Rodrigues, C.; Rodrigues, P.F.; Lopes, A.; Silva, R.J.; Caldeira, J.; Duarte, M.P.; Fernandes, F.B.; Coelhoso, I.M.; et al. Physical and Morphological Characterization of Chitosan/Montmorillonite Films Incorporated with Ginger Essential Oil. Coatings 2019, 9, 700. [CrossRef]

49. Cho, S.; Jang, J.-W.; Jung, S.-H.; Lee, B.R.; Oh, E.; Lee, K.-H. Precursor Effects of Citric Acid and Citrates on ZnO Crystal Formation. Langmuir 2009, 25, 3825-3831. [CrossRef]

50. Bettini, S.; Pagano, R.; Bonfrate, V.; Maglie, E.; Manno, D.; Serra, A.; Valli, L.; Giancane, G. Promising Piezoelectric Properties of New ZnO@Octadecylamine Adduct. J. Phys. Chem. C 2015, 119, 20143-20149. [CrossRef]

51. Vandecasteele, C.; Block, C.B. Modern Methods for Trace Element Determination; Wiley: Hoboken, NJ, USA, 1997; ISBN 978-0-471-97445-1.

52. Pascoal, A.; Quirantes-Piné, R.; Fernando, A.L.; Alexopoulou, E.; Segura-Carretero, A. Phenolic composition and antioxidant activity of kenaf leaves. Ind. Crop. Prod. 2015, 78, 116-123. [CrossRef]

53. Ramesh, M.; Anbuvannan, M.; Viruthagiri, G. Green synthesis of ZnO nanoparticles using Solanum nigrum leaf extract and their antibacterial activity. Spectrochim. Acta Part A Mol. Biomol. Spectrosc. 2015, 136, 864-870. [CrossRef] [PubMed]

54. Jafarirad, S.; Mehrabi, M.; Divband, B.; Kosari-Nasab, M. Biofabrication of zinc oxide nanoparticles using fruit extract of Rosa canina and their toxic potential against bacteria: A mechanistic approach. Mater. Sci. Eng. C 2016, 59, 296-302. [CrossRef]

55. Pavithra, N.; Lingaraju, K.; Raghu, G.; Nagaraju, G. Citrus maxima (Pomelo) juice mediated eco-friendly synthesis of ZnO nanoparticles: Applications to photocatalytic, electrochemical sensor and antibacterial activities. Spectrochim. Acta Part A Mol. Biomol. Spectrosc. 2017, 185, 11-19. [CrossRef] [PubMed]

56. Nava, O.; Soto-Robles, C.; Gómez-Gutiérrez, C.; Vilchis-Nestor, A.; Castro-Beltrán, A.; Olivas, A.; Luque, P. Fruit peel extract mediated green synthesis of zinc oxide nanoparticles. J. Mol. Struct. 2017, 1147, 1-6. [CrossRef]

57. Çolak, H.; Karaköse, E.; Duman, F. High optoelectronic and antimicrobial performances of green synthesized ZnO nanoparticles using Aesculus hippocastanum. Environ. Chem. Lett. 2017, 15, 547-552. [CrossRef] 
58. Sorbiun, M.; Mehr, E.S.; Ramazani, A.; Fardood, S.T. Green Synthesis of Zinc Oxide and Copper Oxide Nanoparticles Using Aqueous Extract of Oak Fruit Hull (Jaft) and Comparing Their Photocatalytic Degradation of Basic Violet 3. Int. J. Environ. Res. 2018, 12, 29-37. [CrossRef]

59. Ahmed, S.; Annu; Chaudhry, S.A.; Lkram, S. A review on biogenic synthesis of ZnO nanoparticles using plant extracts and microbes: A prospect towards green chemistry. J. Photochem. Photobiol. B Biol. 2017, 166, 272-284. [CrossRef]

60. Soliman, M.M.A.; Alegria, E.C.B.A.; Ribeiro, A.P.C.; Alves, M.M.; Saraiva, M.S.; Montemor, M.F.; Pombeiro, A.J.L. Green synthesis of zinc oxide particles with apple-derived compounds and their application as catalysts in the transesterification of methyl benzoates. Dalton Trans. 2020, 49, 6488-6494. [CrossRef]

61. Thema, F.; Manikandan, E.; Dhlamini, M.; Maaza, M. Green synthesis of ZnO nanoparticles via Agathosma betulina natural extract. Mater. Lett. 2015, 161, 124-127. [CrossRef]

62. Singh, A.; Singh, N.B.; Afzal, S.; Singh, T.; Hussain, I. Zinc oxide nanoparticles: A review of their biological synthesis, antimicrobial activity, uptake, translocation and biotransformation in plants. J. Mater. Sci. 2018, 53, 185-201. [CrossRef]

63. Clinical and Laboratory Standards Institute (CLSI). Performance Standards for Antimicrobial Susceptibility Testing; Twenty-Fifth Informational Supplement, CLSI Document M100-S25; CLSI: Wayne, PA, USA, 2015; ISBN 1562388975.

64. European Food Safety Authority (EFSA). European food safety authority panel on food contact materials, Enzymes, flavourings and processing aids; Scientific opinion on the safety assessment of the substance zinc oxide, nanoparticles, for use in foo. EFSA J. 2016, 14, 4408-4416.

65. Salarbashi, D.; Mortazavi, S.A.; Noghabi, M.S.; Bazzaz, B.S.F.; Sedaghat, N.; Ramezani, M.; Shahabi-Ghahfarrokhi, I. Development of new active packaging film made from a soluble soybean polysaccharide incorporating ZnO nanoparticles. Carbohydr. Polym. 2016, 140, 220-227. [CrossRef]

66. Espitia, P.J.P.; Soares, N.D.F.F.; Teófilo, R.F.; Coimbra, J.S.D.R.; Vitor, D.M.; Batista, R.A.; Ferreira, S.O.; de Andrade, N.J.; Medeiros, E.A.A. Physical-mechanical and antimicrobial properties of nanocomposite films with pediocin and $\mathrm{ZnO}$ nanoparticles. Carbohydr. Polym. 2013, 94, 199-208. [CrossRef]

67. Noshirvani, N.; Ghanbarzadeh, B.; Mokarram, R.R.; Hashemi, M.; Coma, V. Preparation and characterization of active emulsified films based on chitosan-carboxymethyl cellulose containing zinc oxide nano particles. Int. J. Biol. Macromol. 2017, 99, 530-538. [CrossRef]

68. Souza, V.G.L.; Pires, J.R.; Rodrigues, P.F.; Lopes, A.A.; Fernandes, F.M.B.; Duarte, M.P.; Coelhoso, I.M.; Fernando, A.L. Bionanocomposites of chitosan/montmorillonite incorporated with Rosmarinus officinalis essential oil: Development and physical characterization. Food Packag. Shelf Life 2018, 16, 148-156. [CrossRef]

69. Pires, J.R.A.; de Souza, V.G.L.; Fernando, A.L. Chitosan/montmorillonite bionanocomposites incorporated with rosemary and ginger essential oil as packaging for fresh poultry meat. Food Packag. Shelf Life 2018, 17, 142-149. [CrossRef]

70. Ferreira, A.R.V.; Alves, V.D.; Coelhoso, I.M. Polysaccharide-Based Membranes in Food Packaging Applications. Membranes 2016, 6, 22. [CrossRef]

71. Cerisuelo, J.P.; Alonso, J.; Aucejo, S.; Gavara, R.; Hernández-Muñoz, P. Modifications induced by the addition of a nanoclay in the functional and active properties of an EVOH film containing carvacrol for food packaging. J. Membr. Sci. 2012, 423-424, 247-256. [CrossRef]

72. Lagaron, J.M.; Catalá, R.; Gavara, R. Structural characteristics defining high barrier properties in polymeric materials. Mater. Sci. Technol. 2004, 20, 1-7. [CrossRef]

73. Baek, S.-K.; Bin Song, K. Development of Gracilaria vermiculophylla extract films containing zinc oxide nanoparticles and their application in smoked salmon packaging. LWT 2018, 89, 269-275. [CrossRef]

74. Baskar, D.; Kumar, T.S. Effect of deacetylation time on the preparation, properties and swelling behavior of chitosan films Carbohydr. Polym. 2009, 78, 767-772. [CrossRef]

75. Mayachiew, P.; Devahastin, S. Effects of drying methods and conditions on release characteristics of edible chitosan films enriched with Indian gooseberry extract. Food Chem. 2010, 118, 594-601. [CrossRef]

76. Peng, Y.; Li, Y. Combined effects of two kinds of essential oils on physical, mechanical and structural properties of chitosan films. Food Hydrocoll. 2014, 36, 287-293. [CrossRef]

77. Jridi, M.; Hajji, S.; Ayed, H.B.; Lassoued, I.; Mbarek, A.; Kammoun, M.; Souissi, N.; Nasri, M. Physical, structural, antioxidant and antimicrobial properties of gelatin-Chitosan composite edible films. Int. J. Biol. Macromol. 2014, 67, 373-379. [CrossRef] [PubMed] 